\title{
Impacts of the monolingual and bilingual dictionaries on the lexical errors committed by EFL learners in Hong Kong: a semantic analysis
}

\author{
Chi Wui Ng $^{1}$
}

Received: 23 October 2015/Accepted: 17 February 2016/Published online: 2 March 2016

(C) Springer-Verlag Berlin Heidelberg 2016

\begin{abstract}
Drawing upon semantic theories and concepts, including argument structure, componential analysis, descriptive meaning, and syntagmatic constraints, the present study analyses the four typical lexical errors committed by EFL learners in Hong Kong identified in a previous study conducted by Chan (TESOL Quarterly $44: 295-319,2010)$ and investigates whether the lexical information provided in monolingual and bilingual dictionaries alleviates or aggravates those four errors, respectively. The lexical information in monolingual dictionaries has been discovered to be efficacious in filling the gaps in learners' lexical knowledge and assisting them in alleviating those errors, whilst that in bilingual dictionaries has been found to be capable of alleviating only the types of errors not influenced by the learners' L1 but aggravating the errors influenced by the L1. The current study has provided pedagogical implications for the instruction of English vocabulary in the context of Hong Kong, albeit learners' comprehension of the dictionary entries has to be investigated in the future to verify the findings of the study.
\end{abstract}

Keywords Lexical errors · Hong Kong EFL learners · Monolingual dictionaries · Bilingual dictionaries

\section{Introduction}

In accordance with the grammatical hierarchy, the hierarchical ordering of grammatical units, a sentence comprises one or more clauses, each of which consists of one or more phrases (Nelson 1998). Phrases can be further broken down into words, which can be construed as the building blocks of meaningful discourse

Chi Wui Ng

ngchiwui@link.cuhk.edu.hk

1 The Chinese University of Hong Kong, Room G01, Ho Tim Building, Shatin, New Territories, Hong Kong China 
in any languages. It is thereby of vital importance for second or foreign language learners to enrich the vocabulary of the target languages, which is required for them to express their ideas clearly and accurately. It is even contended by scholars in the field of second and foreign language acquisition, such as Ellis $(2002,2006)$, that the acquisition of lexical items is the premise of the learning of syntactic rules; this establishes the significance of vocabulary learning. There appears to be a widespread misconception that knowing a word is tantamount to understanding its literal meaning, or its sense from a semantic perspective, albeit it is a no-brainer that the lexical information conveyed by a single word is much more than its sense. All the same, what is considered 'the knowledge of a word' is highly contentious, which makes it extremely difficult to judge or tell whether a person has acquired a certain lexical item.

Distinct linguists, in particular semanticists, possess disparate sentiments concerning 'the knowledge of a word' and so have proposed discrepant schemata illustrating their tenets. On the basis of the schemata proposed by Fillmore (1971), Richard (1976), Carter (1987), and Nation (2001), 11 types of lexical information that are considered segments of 'the knowledge of a word' can be summarized and enumerated in Table 1.

Amongst the aforementioned 11 types of lexical information, the first 3 and the last 2 are more closely correlated with phonetics, morphology, and pragmatics and so are not the predominant concerns of this study, which is a semantic analysis. Attributed to the distinct opinions held by different scholars, by no means is it plausible for the above list to be exhaustive, yet it is reckoned to be reasonable to lay a claim that a person has truly learnt a word given that $\mathrm{s} / \mathrm{he}$ has procured the knowledge on those 11 types of lexical information of the word.

Learners making lexical errors, instead, indicates that they lack or have misunderstood certain types of lexical information and so have not comprehensively acquired the lexical item. Distinct types of errors are committed by discrepant populations of learners; Chan (2010) conducted an extensive research project on the pervasive morphosyntactic errors committed by English as a Foreign Language (EFL) learners in Hong Kong, providing an overview of the prevalent errors at the morphological, lexical, syntactic, and discourse levels detected in the English written pieces produced by Hong Kong students.

Besides an elaborated delineation of the errors committed by Hong Kong students, the plausible sources of those errors have also been identified in the study: interference from the mother tongue (L1), lack of positive transfer from the L1, and low language awareness of the target language (Chan 2010). Interference denotes the negative transfer of the linguistic knowledge of the L1 to the production of the target language out of the disparities in linguistic features between the two language systems (Chan 2010; Ellis 1997), whilst the lack of positive transfer from the L1 implies learners' difficulty in acquiring the linguistic features of the target language by virtue of the lack of equivalents in their L1 (Chan 2010; Ortega 2009; Yule 2014). Whereas the two aforementioned factors can be regarded as being inevitable, low language awareness of the target language is unequivocally a factor that can be avoided as long as learners take heed of the usage of words more meticulously (Chan 2010). These factors cause learners to lack or misunderstand certain lexical information of vocabulary items, effectuating the various lexical errors committed 
by them. Whatever the reason the lexical errors committed by EFL learners in Hong Kong are accounted for, those errors are fatal in the sense that they may hinder the transmission of ideas and thereby have to be tackled seriously.

Presenting the lexical information of vocabulary items, dictionaries are widely perceived to be efficient language-learning tools, for it is not uncommon to see learners looking up dictionaries for difficult words while reading. However, it is doubtful whether the lexical information provided in dictionaries is also sufficient in helping learners acquire the usage of words and avoid lexical errors, filling the gaps in their lexical knowledge or clarifying their misconceptions about certain lexical knowledge. Moreover, dictionaries can largely be categorized into two types: monolingual and bilingual; these two types of dictionaries may differ in terms of the efficacy in helping learners avoid lexical errors. The current study thereby aims at investigating the impacts of monolingual and bilingual dictionaries on the lexical errors committed by EFL learners in Hong Kong. In other words, it is hoped to find out whether the two types of dictionary avoid or aggravate the lexical errors committed by EFL learners in Hong Kong, respectively.

This research topic is certainly integral to the field, in that the results can provide EFL learners with insights into ways to avoid their lexical errors, such as whether to count on dictionaries and whether to employ monolingual or bilingual dictionaries for the sake of avoiding errors. Given that dictionaries are discovered to be efficacious in achieving the aforementioned purpose, EFL teachers ought to encourage students to utilize dictionaries more often and instruct them on dictionary skills, so that learners will be capable of acquiring certain lexical information and avoiding lexical errors through dictionaries. In contrast, given that dictionaries are found out to be ineffectual, rather than relying on dictionaries, EFL teachers may have to carry out semantic analysis of lexical items in class in a bid to equip learners with the required lexical information for them to avoid lexical errors. Barely does the present study aim at investigating whether the errors committed by EFL learners are attributable to the consultation of monolingual or bilingual dictionaries; instead, it is only intended to find out whether those two types of dictionary are capable of providing learners with sufficient information to acquire a comprehensive understanding of a lexical item for the sake of avoiding lexical errors. It may be argued that Hong Kong is only a small place in the world, so it is barely worth conducting a study on the lexical errors committed by EFL learners there. As a matter of fact, EFL learners in Hong Kong possess a one-of-a-kind attribute of being biliteral and trilingual, implying that they manage to master both written Chinese and English as well as spoken Cantonese, Putonghua, and English. Hardly can such a linguistic repertoire be found amongst learners in any other places in the world; so the lexical errors committed by EFL learners in Hong Kong should be unique and are worthy of investigation.

\section{Literature review}

The present research project is concerned about three issues: the analysis of the lexical errors committed by EFL students in Hong Kong, the efficacy of dictionaries in avoiding learners' lexical errors, and the comparison between the impacts of 
monolingual and bilingual dictionaries on learners, each of which has been addressed by previous studies.

\subsection{Analysis of the lexical errors committed by EFL students in Hong Kong}

Apart from Chan (2010), Chu (2005) as well as Jim (2005) has conducted similar research, though on a much smaller scale than that conducted by Chan, investigating the errors committed by EFL learners in Hong Kong. For all the discrepancy in the way in which the errors are categorized, all three studies are capable of detailing different types of errors committed by learners with concrete and specific examples from authentic works produced by students. They also manage to correlate the errors with myriads of second or foreign language acquisition theories or concepts like transfer and overgeneralization (Chan 2010; Chu 2005; Jim 2005).

These studies, however, fail to analyse the lexical errors from a semantic perspective. The analysis of the lexical errors through a semantic approach is extremely significant inasmuch as language is adopted to express meaning, so never can language forms be dissociated from meaning. Only by understanding the difference in the meanings expressed by two words can learners decipher the reason why one word in lieu of the other has to be used in a particular context. Therefore, not only can the application of semantic theories and concepts in the analysis of the lexical errors provide concrete explanations for the errors and suggest how the wrong use of words can effectuate disruptions in the conveyance of meaning, but it can also reveal the gaps in learners' lexical knowledge accurately. Attributed to the lack of semantic analysis of learners' errors in the past, a study addressing learners' lexical errors from such a perspective is necessary and meaningful.

Despite having delineated and accounted for the errors committed by EFL learners in length, the previous studies fail to suggest plausible means for learners to avoid future errors. After the possession of some understanding of the lexical errors committed by EFL learners in Hong Kong, it is vital to find out or propose some ways to assist learners in avoiding them in the future. The ideal avenue of avoiding lexical errors is the acquisition of the information of a lexical item on a holistic basis; perceived to be sources where people usually learn new words, dictionaries appear to be potential sources on which people can rely in a bid to decipher the usage of lexical items comprehensively and avoid lexical errors in the future. It is thereby worth investigating whether monolingual and bilingual dictionaries can truly help learners achieve the aforementioned goals.

\subsection{Efficacy of dictionaries in avoiding learners' lexical errors}

Barely is the relationship between lexical errors and learners' dictionaries a popular research topic in the field, since only little relevant research has been conducted to date. Meara and English (1987) have conducted research on the effectiveness of monolingual learners' dictionaries in EFL learners' correction of lexical errors. Pronounced and remarkable results have been derived from that study: dictionaries manage to identify and provide explanations for learners' lexical errors in most cases, yet usually fail to assist learners in correcting their errors or telling learners 
the right word to use (Meara and English 1987). There is no question that this research project is insightful; however, it lays emphasis on error correction in lieu of avoiding lexical errors, and scarcely does the study target lexical errors committed by Hong Kong students, but EFL learners as a whole. In addition, error correction is largely distinct from avoiding lexical errors, for the former can be treated as a remedial measure to deal with learners' lexical errors whilst the latter is seen as a preventive measure precluding learners from making errors, which appears much more profitable to learners (Table 2).

Chan (2011) has investigated whether monolingual dictionaries manage to assist EFL learners in Hong Kong in determining the meanings of lexical items. The study reveals the efficacy of monolingual dictionaries for meaning determination to a certain extent whilst uncovering that the facilitating effects of monolingual dictionaries are dependent on external variables like the perceptions and attitudes of learners (Chan 2011). Nevertheless, barely does the study draw connections between lexical information presented in the dictionary entries and the lexical errors committed by EFL learners in Hong Kong. Instead, it only presents a discussion on the relationship between dictionaries and meaning determination of some vocabulary items applied in unfamiliar contexts. The present study can then fill the aforementioned gaps in the body of literature.

Table 1 Eleven types of lexical information

\begin{tabular}{|c|c|}
\hline Lexical information & Descriptions \\
\hline Spelling & The orthographic shape of a word \\
\hline $\begin{array}{l}\text { Phonetic } \\
\text { representation }\end{array}$ & The phonological shape of a word \\
\hline $\begin{array}{l}\text { Morphological } \\
\text { structure }\end{array}$ & $\begin{array}{l}\text { The morphemes of which a word is made up and those that can be added to the } \\
\text { word }\end{array}$ \\
\hline Sense and denotation & $\begin{array}{l}\text { The relationship between a linguistic expression and other linguistic expressions } \\
\text { as well as that between the linguistic expression and the external world }\end{array}$ \\
\hline Semantic value & $\begin{array}{l}\text { The componential analysis of the word into a combination of minimal semantic } \\
\text { features }\end{array}$ \\
\hline $\begin{array}{l}\text { Paradigmatic sense } \\
\text { relations }\end{array}$ & The relationships between a lexical item and other lexical items in the language \\
\hline $\begin{array}{l}\text { Syntagmatic sense } \\
\text { relations }\end{array}$ & The relationships amongst lexical items in the same sentence \\
\hline Collocations & $\begin{array}{l}\text { The words with which the target word co-occurs as well as some fixed } \\
\text { expressions where the target word can be found }\end{array}$ \\
\hline Argument structure & $\begin{array}{l}\text { The number of arguments taken by the word as well as the thematic roles of each } \\
\text { argument }\end{array}$ \\
\hline $\begin{array}{l}\text { Non-descriptive } \\
\text { meaning }\end{array}$ & The expressive and evoked meanings of the word \\
\hline Presuppositions & The fallacy conditions associated with the usage of a word in utterances \\
\hline
\end{tabular}

Sources Carter, Ronald. 1987. Vocabulary: applied linguistics perspectives. Boston: Unwin Hyman. Fillmore, Charles J. 1971. Types of lexical information. In Semantics: an interdisciplinary reader in philosophy, linguistics and psychology, ed. Danny D. Steinberg, and Leon A. Jakobovits, 373-392. London: Cambridge University Press. Nation, I.S.P. 2001. Learning vocabulary in another language. Cambridge: Cambridge University Press. Richard, Jack C. 1976. The role of vocabulary teaching. TESOL Quarterly 10:77-89 
Table 2 Different thematic roles

\begin{tabular}{|c|c|}
\hline $\begin{array}{l}\text { Thematic } \\
\text { roles }\end{array}$ & Descriptions \\
\hline Agent & $\begin{array}{l}\text { An animate instigator of an action that supplies the energy for the action and acts } \\
\text { deliberately }\end{array}$ \\
\hline Force & An inanimate instigator of an action \\
\hline Instigator & $\begin{array}{l}\text { An animate instigator of an action that acts deliberately, but does not supply the energy } \\
\text { for the action }\end{array}$ \\
\hline Effector & $\begin{array}{l}\text { An animate instigator of an action that supplies the energy for the action, but does not act } \\
\text { deliberately }\end{array}$ \\
\hline Instrument & An animate force or object casually involved in an action \\
\hline Experiencer & An animate instigator being affected by a state or action \\
\hline Benefactory & An animate instigator being benefited \\
\hline Recipient & An animate instigator receiving something \\
\hline Factitive & $\begin{array}{l}\text { An object or being resulting from an action or state that is understood as part of the } \\
\text { meaning of the predicate }\end{array}$ \\
\hline Locative & The location or spatial orientation of a state or action \\
\hline Source & The location from which something moves \\
\hline Path & The spatial orientation through which something moves \\
\hline Goal & The location to which something moves \\
\hline Theme & $\begin{array}{l}\text { An animate entity affected by an action or state that remains unchanged after the process } \\
\text { or action }\end{array}$ \\
\hline Patient & An animate entity affected by an action or state that is changed after the process or action \\
\hline
\end{tabular}

Source Cruse, Alan. 2011. Meaning in Language: An Introduction to Semantics and Pragmatics. 3rd ed. Oxford: Oxford University Press

\subsection{Impacts of monolingual and bilingual dictionaries on learners}

The controversy over whether monolingual or bilingual dictionaries are more suitable or beneficial for learners in terms of avoiding lexical errors pertains to the debate over whether the L1 should be adopted in second or foreign language instruction. On one hand, the L1 is seen as a facilitating tool that assists learners in comprehending complicated or difficult concepts in the target language better (Cook 2001; Turnbull 2001). On the other hand, the L1 may be argued to aggravate the problem of interference, which is disastrous to learners (Littlewood and Baohua 2011). Thomson (1987) has conducted a research on the advantages and disadvantages of bilingual dictionaries over monolingual dictionaries.

The overriding good of monolingual dictionaries is that they expose learners to the target language. It is of paramount importance for all language learners, whether first language or second language learners, to have themselves exposed to the language in a bid to understand how the language can be utilized in real contexts (Turnbull 2001). Defining words in English, English monolingual dictionaries undoubtedly enhance learners' exposure to English (Thomson 1987). However, it may be difficult for learners to interpret the definitions provided in monolingual 
dictionaries every now and then on account of the circularity in the definitions (Thomson 1987). The prerequisite for understanding the definition of a lexical item is that learners have to understand all the words that are employed to define the target lexical item. Given that they have difficulty understanding those words in the definition, barely is it plausible for them to understand the definition.

Concerning bilingual dictionaries, the predominant benefit is that learners can understand the definitions of words in their L1 much more easily. In accordance with some psycholinguistic research, disparate languages constitute a unitary language system in the human mind, so the linguistic knowledge of one language can facilitate the uptake of linguistic knowledge of another (Cook 2001). This elucidates why EFL learners possess the tendency to use bilingual dictionaries in lieu of monolingual dictionaries (Thomson 1987). Even so, bilingual dictionaries may encourage learners to directly translate from the L1 to the target language, providing learners with an impression that one-to-one equivalents do exist between two linguistic systems, which is indeed not the case (Thomson 1987). Furthermore, direct translations usually fail to adequately depict the syntactic behaviour of words, effectuating the lexical errors committed by learners (Thomson 1987).

The chief strengths and weaknesses of monolingual and bilingual dictionaries have been presented above, yet scarcely do they zero in on the relationship between the dictionaries and the learners' lexical errors. The present study is thereby going to make an attempt to compare the two types of dictionaries in terms of their impacts on the lexical errors committed by EFL learners in Hong Kong.

\section{The study}

\subsection{Research questions}

For the sake of addressing the research topic systematically, two research questions have been devised:

1. Does the lexical information provided in monolingual dictionaries avoid or aggravate the lexical errors committed by EFL learners in Hong Kong?

2. Do the Chinese translations in bilingual dictionaries alleviate or aggravate the lexical errors committed by EFL learners in Hong Kong?

The entire study will commence with a semantic analysis of the lexical errors committed by EFL learners in Hong Kong, which is the application of semantic theories or concepts to illustrate or elucidate the lexical errors. Any gaps or misconceptions in learners' lexical knowledge will be identified. Following the semantic analysis of lexical errors are the analyses of relevant entries in monolingual and bilingual dictionaries.

Regarding the first research question, the lexical information provided in monolingual dictionaries will be analysed with respect to the gaps or misconceptions in learners' lexical knowledge. Only when dictionaries are capable of providing concrete, accurate, and holistic lexical information for learners can they 
help learners avoid lexical errors. In contrast, given that the lexical information in dictionaries is insufficient, confusing, and even misleading, never can they provide assistance to learners, and they may even aggravate learners' lexical errors.

As for the second research question, the method by which the analysis is conducted will be more or less similar to that adopted in the first question, except that the targets of the analysis will no longer be the lexical information presented in English but the Chinese translations in bilingual dictionaries.

\subsection{Methodology}

The language production of EFL learners in Hong Kong has to be collected in the first place so that the errors in the language production can be identified and analysed. Since it is implausible to collect the written works produced by every EFL learner in Hong Kong for analysis, only certain samples can be collected for analysis. Rather than undergoing an extensive procedure of data collection, the present study is going to build upon the study conducted by Chan (2010), which collected free-writing samples from lower intermediate, upper immediate, and advanced EFL learners in Hong Kong, identified the errors in the written samples, and categorized the errors. Four types of lexical errors have been identified in the study, namely inaccurate directionality, synonym confusion, vocabulary compensation, and synforms, respectively (Chan 2010). These four types of error will be used for analysis in the present study. The decision to build upon the data collected in a previous study in lieu of collecting original data for analysis can be justified in two ways. Firstly, Chan (2010) conducted a large-scale and comprehensive research study on errors committed by EFL learners in Hong Kong with a meticulous and well-designed procedure of data collection. The lexical errors identified in Chan (2010) are also reckoned to be representative of those committed by EFL learners in Hong Kong inasmuch as the sample size of that study is the largest amongst all studies of the same nature, and works produced by learners at varying levels were collected, making the data reliable and convincing. Secondly, it is desirable to conduct further analysis of the data collected in some past research so that tighter connections can be built amongst distinct studies within the same field, and readers can make better sense of the objectives as well as data analysis of the present study. However, even though the present study builds upon the study conducted by Chan (2010), the data analysis, which is the semantic analysis of the errors identified as well as the linkage between those errors and dictionary entries, still demonstrates originality.

The Oxford Advanced Learner's Dictionary (OALD) and the Oxford Advanced Learner's English-Chinese Dictionary (OALED) are the monolingual and bilingual dictionaries adopted for data analysis in the present research, respectively. The relevant entries of these two dictionaries will be examined to find out whether these two dictionaries provide sufficient and accurate lexical information for learners to avoid the lexical errors identified or provide misleading or vague lexical information that may plausibly mislead learners into committing the errors. The reason why the OALD is selected is that not only is it the best-selling advanced learner's dictionary worldwide, but it is also the monolingual dictionary recommended by most 
secondary schools in Hong Kong, implying that it is probably the English monolingual learner's dictionary with the most users in Hong Kong (Oxford Advanced Learner's Dictionary 2015). Being the bilingual version of the OALD, the OALED possesses exactly the same lexical information as the OALD does, except that Chinese translations are incorporated into each lexical entry.

\subsection{Data analysis}

Multifaceted semantic theories and concepts will be employed in the analysis of the lexical errors committed by EFL learners in Hong Kong.

\subsubsection{Argument structure}

Arguments, which designate some entity or group of entities, can be realized by either noun phrases or clauses, whilst predicates, which attribute some property to the entity denoted by arguments, can be realized by the overwhelming majority of phrases whose heads are content words, such as noun phrases, verb phrases, adjective phrases, and adverb phrases (Cruse 2011; Fillmore 1971). Each predicate takes a certain number of arguments, which can be expressed in terms of the argument structure. Other than the number of arguments taken, the thematic roles played by each argument, which are the relationships between each argument and the predicate, are also shown in the argument structure of the predicate (Cruse 2011). Even if some lexical items behave in a similar manner syntactically, they can possess entirely disparate argument structures, which can be one of the avenues for accounting for differences in their meaning; this explains why argument structure is part and parcel of semantics and so is important in illustrating the lexical errors committed by learners.

By no means is the categorization of thematic roles unanimous, but discrepant semanticists have proposed distinct sets of thematic roles instead. The set of thematic roles adopted for analysis in the present project was originally proposed by Fillmore and later modified by Cruse (2011). Such a set of thematic roles was selected owing to its comprehensiveness and meticulousness. Fifteen thematic roles can be categorized; each of them is briefly illustrated as follows.

\subsubsection{Componential analysis}

The basis of the approach of componential analysis is that the meaning of a lexical item can be seen as a combination of semantic atoms, the smallest units of meaning; so the sense of a word can be decomposed into a combination of semantic atoms (Cruse 2011). Discrepant semanticists have proposed distinct approaches to componential analysis; the approach adopted in the present study is classical structuralism proposed by Hjelmslev, which merely breaks down the meaning of a word into a combination of minimal semantic atoms (Cruse 2011). Barely will the binarist principles be taken into consideration, since semantic atoms do not always exist in pairs, and so imparting a positive or negative value to each semantic atom may add complication to the entire process of analysis. 
Componential analysis is definitely an efficacious avenue of identifying differences in meaning between two or more lexical items and whether those lexical items are only slightly or entirely distinct in meaning. Given that two lexical items are made up of distinct semantic atoms, it can be concluded that their meanings are discrepant from each other to a certain extent. This analytical method is thereby a useful way of providing explanations for lexical errors committed by learners, elucidating why hardly the correct word and the incorrect word can be substituted for each other without changing the expressed meaning.

\subsubsection{Parameters of descriptive meaning}

Descriptive meaning, which is the aspect of meaning determining the truth conditions of the proposition expressed, involves several parameters: quality, intensity, specificity, and vagueness (Cruse 2011). Given that two lexical items differ from each other in any of these parameters, they can be said to possess distinct descriptive meanings. Certain tests or concepts can be conducted or employed to test whether two lexical items differ from each other in terms of any of the parameters. For instance, "not X, but Y" can be employed to identify discrepancies in quality, whilst "not only $\mathrm{X}$, but also $\mathrm{Y}$ " can be adopted to identify discrepancies in intensity (Cruse 2011). Also, the parameter of specificity is pertinent to the paradigmatic sense relations of hyponymy or meronymy, whereas vagueness concerns ill-definedness or laxness (Cruse 2011).

Influencing the truth conditions of the proposition expressed, descriptive meaning can be considered the crux of meaning and so can be used to illustrate the lexical errors committed by learners. Given that two lexical items are found out to possess distinct descriptive meanings, it can be argued that replacing one of them with another does alter the core meaning expressed and so is regarded as a lexical error.

\subsubsection{Syntagmatic constraints}

In spite of being a separate field in linguistics, syntax is interrelated with semantics in the sense that certain syntactic rules have to be complied with, so that a proposition can be clearly and accurately expressed. Syntagmatic sense relations, which denote the relationships held amongst lexical items in the same sentence, can be construed as the interactions between semantics and syntax. One principal area of concern in such sense relations is the co-occurrence of lexical items (Cruse 2011). Some lexical items can occur together, whilst some do not; such syntagmatic constraints are directional at times. Lexical items known as selectors impose limitations on the selectees, which are lexical items that can co-occur with the selectors; any violations of the syntagmatic constraints effectuate semantic clash, which is a kind of semantic anomaly (Cruse 2011). Suffice it to say that any semantic clashes indicate lexical errors; the analysis of syntagmatic constraints of lexical items is thereby a plausible method to identify and elucidate lexical errors committed by learners. 


\subsubsection{Grammatical structure}

Even though the present study is a semantic analysis, being interrelated with semantics, syntax can be treated as a supplement to the aforementioned semantic theories and concepts, playing an indispensable role in the understanding of lexical errors committed by learners. The analysis of the grammatical structure of sentences may not be capable of providing clear and direct explanations for the lexical errors committed by learners, albeit such analysis may be useful in illustrating the grammatical functions performed by many a lexical item in a sentence, which can help with the illustrations of the syntagmatic constraints of lexical items. The grammatical structure of sentences can be put forward through grammatical descriptions.

\section{Results}

The four lexical errors committed by EFL learners in Hong Kong that have been identified by Chan (2010) will be analysed separately.

\subsection{Inaccurate directionality}

This type of error is associated with the concept of converses, a subtype of directional opposite in paradigmatic sense relations of exclusion and opposition (Cruse 2011). Consider the following pair of sentences:

(1a) A is in front of B.

(1b) $\mathrm{B}$ is behind $\mathrm{A}$.

As a matter of fact, both sentences (1a) and (1b) denote the same situation, but delineate such a situation from two distinct perspectives. Sentence (1a) has "A" as the subject of the sentence and " $\mathrm{B}$ " as part of the information focus of the sentence, whilst sentence (1b) has "B" as the subject of the sentence and "A" as part of the information focus of the sentence. The prepositions "in front of" and "behind" are thereby said to be converses, which refer to the same situation but are opposites of each other in terms of directionality. Seldom do EFL learners in Hong Kong have difficulty distinguishing between "in front of" and "behind", which are considered elementary words, but they appear to possess difficulty distinguishing between converses that are verbs (Chan 2010). Compare the following set of sentences:

(2a) *I borrowed money to him.

(2b) I lent money to him.

(2c) I borrowed money from him.

It is observed that some EFL learners in Hong Kong fail to distinguish between the verbs lend and borrow; in particular, they are uncertain about the usage of the verb lend and so overgeneralize the usage of borrow. Sentence (2a) is a real 
sentence produced by an EFL learner in Hong Kong extracted from Chan (2010), which is ungrammatical, whilst sentence $(2 b)$ should be the grammatical sentence that expresses the proposition intended to be expressed by the student producing sentence (2a). This error can first be explained in terms of the argument structures of the two verbs. Consider the following:

(3a) Lend: source $<$ theme, goal $>$.

(3b) Borrow: goal $<$ theme, source $>$.

It can be seen from the above that the thematic roles "source" and "goal" are the external arguments of the predicates and occupy the subject positions of the sentences when lend and borrow are the main verbs of the sentences, respectively. In sentence (2a), the subject of the sentence "I" is the source in lieu of the goal of the action; such a construction thereby violates the argument structure of the verb "borrow" and so is considered ungrammatical. Instead, sentence (2b) is grammatical, for the subject position of the sentence is occupied by "I", who is the source of the action; this complies with the argument structure of the verb lend. Aside from the argument structure, componential analysis can also be employed to illustrate this error:

(4a) Lend $=$ [give] [to somebody] [returned soon].

(4b) $\quad$ Borrow $=$ [get] [from somebody] [return soon].

The componential analyses of lend and borrow reveal that the two verbs are indeed constituted by distinct semantic atoms. Adopting the verb borrow to convey the meaning of "getting something from somebody" in lieu of "giving something to somebody", sentence (2a) is undeniably ungrammatical. Consider also the following test for a parameter of descriptive meaning:

(5a) I did not lend money to him, but I borrowed money from him.

(5b) I did not borrow money from him, but I lent money to him.

The above "not X, but Y" test can be employed to corroborate that the verbs lend and borrow possess distinct descriptive meanings and differ in terms of quality. Being discrepant from each other in core meaning, by no means can the two words be employed interchangeably. As a result, given that sentence (2b) is correct to express the proposition of "I gave money to him and he would return the money to me soon", sentence (2a) is incorrect in that barely is it plausible to express the same proposition as sentence $(2 \mathrm{~b})$ does when a verb with a distinct descriptive meaning is adopted.

With regard to the syntagmatic constraints of the two verbs, the two verbs can be treated as the selectors in sentences that select suitable prepositions followed by them. The selectees of lend and borrow are "to" and "from", respectively; any violations of such syntagmatic constraints lead to ungrammatical constructions. This further elucidates why borrow and "to" cannot co-occur; so sentence (2a) is ungrammatical. 
The aforementioned semantic theories and concepts are capable of explaining why sentence (2a) is ungrammatical, whilst sentence (2b) is grammatical. The reasons why EFL learners in Hong Kong possess a disposition to construct sentence (2a) are that the verbs lend and borrow may be hardly distinguishable in terms of both meaning and grammatical structure. In terms of meaning, both verbs indeed denote the same event, but only differ in directionality, which may confuse learners. What is more, sentences (2b) and (2c) possess the same grammatical structure; sentence (2b) has been much discussed above, whereas sentence (2c) indeed demonstrates the correct usage of the verb borrow. This pair of sentences implies that the verbs lend and borrow behave in the same way syntactically when they are in the form of monotransitive verbs: both sentences possess "I" as the subject, a verb phrase with a predicator and a direct object, and an adverbial realized by a prepositional phrase. Along with the denotation of the same event, the identical syntactic behaviour of the two verbs may have caused confusion to learners.

After the analysis of the error, the relevant dictionary entries will be analysed in a bid to investigate whether the lexical information provided in the entries is sufficient and accurate in a bid to avoid the error committed by learners. The entries of lend and borrow in the OALD can be seen in Figs. 1 and 2, respectively. Notwithstanding the lack of an explicit presentation of the argument structures of the two verbs in the dictionary entries, the two entries are argued to be useful to users in two ways. First and foremost, the two entries present the difference in sense between the two lexical items to readers clearly and accurately by suggesting that the word lend denotes "[giving] something to somebody", whilst the word borrow denotes "[taking] and [using] something that belongs to somebody else"; these definitions have embodied the semantic atoms of which the two words are made up of (Oxford Advanced Learner's Dictionary 2015). Additionally, the syntagmatic constraints of the two verbs are clearly presented in the sense that the prepositions that have to be followed by each verb are overly stated in the entries. Both types of information provided can surely remind learners of the meaning as well as the usage of each verb, assisting them in avoiding the error made in sentence (2a). On this basis of this example, it can then be argued that the lexical information conveyed in monolingual dictionaries is capable of assisting learners in avoiding the error of inaccurate directionality.

The following are the Chinese translations of lend and borrow provided in OALED (Hornby 2004):

1 . [transitive] to give something to somebody or allow them to use something that belongs to you, which they have to return to you later

$\rightarrow$ SYNONYM loan

- lend (out) something (to somebody) I've lent the car to a friend.

- lend somebody something Can you lend me your car this evening?

- Has he returned that book you lent him?

Fig. 1 The entry of Lend in OALD. Source "Oxford Advaned Learner's Dictionary". Oxford University Press. Accessed April 20, 2015. http://www.oxfordlearnersdictionaries.com/ 
1

-. [transitive] to take and use something that belongs to somebody else, and return it to them at a later time

- borrow something Can I borrow your umbrella?

- borrow something from somebody/something Members can borrow up to ten books from the library at any one time.

- borrow something off somebody (British English, informal) I borrowed the DVD off my brother.

$\rightarrow$ COMPARE lend

Fig. 2 The entry of Borrow in OALD. Source "Oxford Advaned Learner's Dictionary." Oxford University Press. Accessed April 20, 2015. http://www.oxfordlearnersdictionaries.com/

(6a) lend: jiè gěi, jiè chū (借給, 借出)

(6b) borrow: jiè, jiè yòng (借, 借用)

These Chinese translations can be utilized to construct the following Chinese sentences:

(7a) Wǒ jiè qián gěi ň̌. 我借錢給你。

I lend money to you

"I lend money to you."

(7b) Wǒ jiè qián. 我借錢。

I borrow money

"I borrow money."

(7c) Wǒ jiè nì. qián.. 我借你錢。

I borrow you money

"I lend you money."

Sentences (7a) and (7b) manifest that the Chinese translations of lend and borrow provided in the OALED, which are 'jiè gěi' and 'jiè', respectively, can assist learners in interpreting the English meanings of the two verbs. Sentence (7c) is however problematic in that the sentence is constructed using the Chinese translation of borrow 'jiè', yet the meaning of the entire sentence is "I lend you money" in lieu of "I borrow money from you". From this instance, it can be established that the expression 'jiè' in Chinese can indeed mean both borrow and lend, depending on the way in which the expression is used. Informed by the OALED in which borrow means 'jiè', and realizing that 'jiè' can also mean lend by referring to their native intuition, EFL learners in Hong Kong may generate a misconception that lend and borrow are equivalents and can mean the same thing; this results in the error made in sentence (2a). The Chinese translations provided in 
bilingual dictionaries may thereby be misleading and aggravate the error of inaccurate directionality committed by EFL learners in Hong Kong.

\subsection{Synonym confusion}

Synonymy is the sense relations between two lexical items such that the two lexical items are interchangeable in some contexts without changing the truth conditions of the proposition expressed. Absolute synonyms, which can be interchangeable in all contexts, are rather rare in practice, but most of the pairs of lexical items possessing the sense relation of synonymy are near synonyms, which are similar to each other in sense and are interchangeable to a certain extent (Cruse 2011). Synonym confusion is a problem in which learners fail to differentiate near synonyms and utilize them inappropriately (Chan 2010). Consider the following pair of sentences:

(8a) I fought you.

(8b) I hit you.

Sentence (8a) is a sentence produced by an EFL learner, albeit the real meaning intended to be expressed should be expressed through sentence (8b). For all the grammaticality of both sentences, the two sentences express essentially distinct propositions out of the distinct meanings expressed by the main verbs; a wrong meaning is thereby conveyed and a lexical error arises when one of them is used in place of the other. The following semantic theories and concepts can help illustrate that the two words cannot be used interchangeably in all contexts, albeit their meanings exhibit similarities. To begin with, consider the componential analyses of the two verbs:

(9a) Fight $=[$ touch $][$ touched $][$ with force $]$.

(9b) Hit $=[$ touch $][$ with force $]$.

From the componential analyses of the two verbs, it can be observed that overlapping exists in the semantic atoms constituting the sense of the two verbs. Both verbs share the meanings of "touching" and "with force", yet fight also possesses the meaning of "being touched", which is not incorporated into the sense of hit. In other words, fight involves the physical action of two people, whilst only hit involves the physical action of one person. It can then be contended that not only do the two verbs possess the relationship of near synonymy, but they also possess the relationship of hyponymy, in which hit is the superordinate and fight is the hyponym, inasmuch as fight entails but is not entailed by hit. Given that you fought somebody, it is correct to say that you hit somebody, which is supported by the fact that the meaning of the verb hit is incorporated into that of fight. In contrast, given that you hit somebody, it may not be correct to say that you fought somebody since part of the meaning of fight is not incorporated into that of hit. Sentence (8a) would thereby be said to be incorrect or inappropriate given that "I" did hit but was not hit by "you". Attributed to the sense relation of hyponymy held between the two lexical items, they differ in descriptive meaning in terms of specificity, which is another 
piece of evidence substantiating that the two verbs possess distinct semantic values and so are not interchangeable in all contexts.

With regard to the syntagmatic constraints of the two verbs, even though both verbs select noun phrases, they impose distinct limitations on the noun phrases selected. Hit can be followed by either animate or inanimate entities, whilst only fight can be followed by animate entities, which can be explained by the fact that the latter involves the physical action of both parties. These syntagmatic constraints can be illustrated by sentences ( $8 a)$ and $(8 b)$ as well as the following pair of sentences:

(10a) *I fought the wall.

(10b) I hit the wall.

Being animate, "you" in sentences (8a) and (8b) can follow both fight and hit despite the difference in the meaning expressed; however, being inanimate, "the wall" following the verb fought gives rise to a semantic clash, which is shown in sentence (10a). Instead, "the wall" following the verb hit produces a well-formed construction, which is shown in sentence (10b).

The componential analysis and the analysis of the syntagmatic constraints of fight and hit have established that hardly can the two verbs be used interchangeably in all contexts; EFL learners' failure to distinguish between the two verbs cannot be accounted for from three perspectives: componential analysis, argument structure, and grammatical structure.

As seen in the componential analyses of the two verbs used above, the semantic atoms constituting the sense of the two verbs are substantially similar, which entails that the two verbs possess substantial similarities in terms of meaning. EFL learners may thereby fail to make a clear distinction between them. Two other avenues of the explanation of this type of lexical error are correlated with the argument structures of the two verbs and the grammatical structures of sentences (8a) and (8b):

(11a) Fight: agent $<$ theme $>$.

(11b) Hit: agent $<$ theme $>$.

In the form of monotransitive verb, the two verbs possess the same argument structure with an agent and a theme as the external and internal arguments of the predicates, respectively. Moreover, sentences (8a) and (8b) possess the same grammatical structure in that each possesses a subject and a verb phrase comprising a predicator and a direct object. The similarities between the two verbs in the aforementioned aspects induce EFL learners in Hong Kong to commit the error of synonym confusion as manifested in sentence (8a).

In the following, the entries of the verbs fight and hit will be analysed in a bid to evaluate whether the lexical information provided in those entries can assist EFL learners in distinguishing between the meanings as well as usage of the two near synonyms. The entries of fight and hit in the OALD can be seen in Figs. 3 and 4, respectively. It can be concluded from the above analysis that fight and hit possess two chief discrepancies: descriptive meaning and syntagmatic constraints. Concerning descriptive meaning, the core difference between the two verbs is the 
2 ㅇ. [intransitive, transitive] fight (somebody) to struggle physically with somebody

- My little brothers are always fighting.

- She'll fight like a tiger to protect her children.

Fig. 3 The entry of Fight in OALD. Source "Oxford Advaned Learner's Dictionary". Oxford University Press. Accessed April 20, 2015. http://www.oxfordlearnersdictionaries.com/

1 . [transitive] to bring your hand, or an object you are holding, against somebody/something quickly and with force

- hit somebody/something My parents never used to hit me.

- hit somebody/something with something He hit the nail squarely on the head with the hammer.

- She hit him on the head with her umbrella.

Fig. 4 The entry of Hit in OALD. Source "Oxford Advaned Learner's Dictionary". Oxford University Press. Accessed April 20, 2015. http://www.oxfordlearnersdictionaries.com/

number of participants involved in the physical action. The definition of fight in the dictionary entry explicitly states that the verb denotes "[struggling] physically with somebody"; the prepositional phrase "with somebody" indicates that two people are involved in physical action (Oxford Advanced Learner's Dictionary 2015). In contrast, hit is defined as "[bringing] your hand ... against somebody/something quickly and with force", which indicates that "you" are the only person engaging in physical action (Oxford Advanced Learner's Dictionary 2015). The two definitions also overly suggest that hit can be followed by animate or inanimate entities, whilst only fight can be followed by animate entities, which is the difference in syntagmatic constraints between the two verbs. It can thereby be concluded that the lexical information provided in monolingual dictionaries are capable of assisting EFL learners in Hong Kong to distinguish between the two near synonyms and so avoid the error of synonym confusion made in sentence (8a).

The Chinese translations of fight and hit provided in OALED are presented below (Hornby 2004):

(12a) fight: bó dòu, dă dòu, dă jià (搏鬥, 打鬥, 打架)

(12b) hit: jī, dă (擊，打)

These Chinese translations can be utilized to construct the following Chinese sentences:

(13a) Wǒ gēn nǐ dă jià. 我跟你打架。

I with you fight

"I fight you." 


Wǒ dă nǐ. 我打你。
I hit you
"I hit you."

(13c) Wǒ dă qiáng bì. 我打牆壁。
I hit c wall

"I hit the wall."

Sentences (13a) to (13c) manifest that the Chinese translations of fight and hit exhibit clear distinctions in both meaning and syntagmatic constraints as the two English verbs do. For instance, the Chinese translations of fight, 'dǎ dòu' and 'dă jià', indicate that the physical action involves two people whilst those of hit, 'jī' and 'dă', indicate that only the physical action is exerted by one participant. In addition, the Chinese translations of hit can co-occur with both animate and inanimate entities, which can be shown in sentences (13b) and (13c), whilst only those of fight co-occur with animate entities; these syntagmatic constraints are the same as those of the two English verbs. The Chinese translations of the two verbs behave similarly as the two English verbs in several aspects, and those Chinese translations provided in bilingual dictionaries are reckoned to be profitable to EFL learners in Hong Kong and manage to help them avoid the error of synonym confusion.

\subsection{Vocabulary compensation}

Vocabulary compensation is similar to synonym confusion in the sense that both denote learners' failure to distinguish between near synonyms, yet the latter pertains to synonyms in the target language whilst the former concerns synonyms in the L1; by no means are the misused word and the correct word inextricable in the target language (Chan 2010). Consider the following pair of sentences:

(14a) *I opened the television.

(14b) I turned on the television.

Open is a monotransitive verb whilst turn on is a phrasal verb comprising a monotransitive verb turn and an adverb on (Greenbaum and Quirk 1990). It is beyond doubt that the two verbs are entirely distinct in meaning, so sentence (16a) is ill-formed; this can be shown through some semantic theories and concepts. First of all, consider the componential analyses of the two:

(15a) Open $=[$ make $][$ not $][$ close $]$.

(15b) Turn on $=$ [cause] [start] [operate].

Made up of entirely distinct semantic atoms, open and turn on possess disparate meanings essentially; the former denotes making something become not close, 
whilst the latter denotes starting the operation of something. It can even be said that the two verbs are distinct in descriptive meaning in terms of quality, which can be corroborated by the "not X, but Y" test:

(16a) I did not open the door of the washing machine, but I turned on the washing machine.

(16b) I did not turn on the washing machine, but I opened its door.

Sentences (16a) and (16b) clearly demonstrate that the actions of opening and turning on something are totally different from each other. It is unquestionably plausible for a person to perform one of those actions without performing the other, which can be seen in each of the sentences (16a) and (16b). In sentence (16a), only did "I" open the door of the door of the washing machine, which had originally been closed, without causing the entire machine to start operating. In contrast, in sentence (16b), only did "I" cause the washing machine, which had not been operating, to start operating without opening the door of the machine. It can thereby be concluded that open and turn on refer to distinct actions and cannot be used interchangeably.

Attributed to the distinction in descriptive meaning between open and turn on, the two verbs differ in terms of syntagmatic constraints. Consider the following set of sentences:

(17a) I opened the window.

(17b) *I opened the light.

(17c) I turned on the light.

(17d) *I turned on the window.

While denoting the action of making something that was closed to be not closed, the verb open can only co-occur with entities that can be in an open or closed condition, which elucidates why sentence (17a) is well formed, whilst sentence (17b) is ill formed: a window is an object that can be either open or closed, whereas light can barely can be in a condition of either open or closed. Denoting the action of causing something to start operation, the phrasal verb turn on can only co-occur with entities that can operate, such as machines, electrical appliances, or some apparatuses. This elucidates why sentence (17c) is well formed, whilst sentence (17d) is ill formed: light is an apparatus that can operate, which produces light energy and heat energy upon operation, whereas a window can hardly operate.

The above discussion on the syntagmatic constraints of open and turn on can provide explanations for the lexical error detected in sentence (14a): barely can a television be in an open or a closed condition or status, so it cannot co-occur with the verb open. Instead, being an electrical appliance that can operate, it ought to cooccur with the phrasal verb turn on as in sentence (14b).

The dictionary entries of open and turn on in the OALD are shown in Figs. 5 and 6 , respectively. These two dictionary entries clearly demonstrate to learners that open denotes the action of "moving [something] so that it is no longer closed", whilst turn on denotes the action of "[starting] the flow of [something]", which possesses a similar meaning as starting the operation of an object (Oxford Advanced 
1 . [transitive] open something to move a door, window, lid, etc. so that it is no longer closed

- Mr Chen opened the car door for his wife.

$\rightarrow$ OPPOSITE close ${ }^{1}$

Fig. 5 The entry of Open in OALD. Source "Oxford Advaned Learner's Dictionary." Oxford University Press. Accessed April 20, 2015. http://www.oxfordlearnersdictionaries.com/

\section{turn something $\leftrightarrow$ on}

to start the flow of electricity, gas, water, etc. by moving a switch, button, etc.

- to turn on the heating

- I'll turn the television on.

- (figurative) He really knows how to turn on the charm (= suddenly become pleasant and attractive).

Fig. 6 The entry of Turn on in OALD. Source "Oxford Advaned Learner's Dictionary." Oxford University Press. Accessed April 20, 2015. http://www.oxfordlearnersdictionaries.com/

Learner's Dictionary 2015). Instances of entities that can co-occur with each of the verbs are also clearly mentioned in the entries: open usually co-occurs with entities like doors or windows whereas turn on usually co-occurs with entities like objects pertinent to the flow of electricity, gas, or water (Oxford Advanced Learner's Dictionary 2015). Reading the two entries, learners can spot and decipher the differences in meaning and usage between the two verbs at ease, which can help them avoid the error shown in sentence (16a); the lexical information provided in monolingual dictionaries can thereby be said to be helpful for EFL learners in Hong Kong to tackle the error of vocabulary compensation.

After the analysis of the lexical information provided in the OALD, the Chinese translations of the two verbs provided in the OALED will be analysed and discussed below (Hornby 2004):

(18a) open: kāi, dǎ kāi, kāi qǔ (開，打開，開啟)

(18b) turn on: jiē tōng, dă kāi (接通, 打開)

These Chinese translations can be utilized to construct the following Chinese sentences:

Dă kāi diàn shì. 打開電視。
open / turn on television
"Turn on the television.”
Dă kāi chuāng. 打開窗。
open / turn on window


(19b) "Open the window."

(19c) Kāi qǐ diàn shì. 開啟電視。
open television
"Turn on the television."

As revealed in sentence (19a) to (19c), the Chinese translations of open and turn on are problematic in two ways, the first of which is the Chinese expression 'dă kāi'. Being the Chinese translations of both open and turn on, such a Chinese expression may provide learners with an impression that the two English verbs are equivalents of each other, which is indeed not the genuine case. This may be one of the reasons why EFL learners in Hong Kong confuse the two words and utilize them interchangeably in their English production, effectuating ungrammatical constructions as in sentence (14a). Another problem with the Chinese translations of the two lexical items concerns the Chinese expression 'kāi qí'. In spite of being one of the Chinese translations of open, "kāi qǔ" can indeed mean 'turn on' in certain contexts, which can be seen in sentence (19c). Informed by the OALED that open means 'kāi qř', and realizing that 'kāi qǔ' can also mean turn on by referring to their native intuition, EFL learners in Hong Kong may generate a misconception that open and turn on are equivalents and can mean the same thing; this brings about the error made in sentence (14a). On the basis of the two aforementioned reasons, it can be concluded that the Chinese translations may not be capable of assisting EFL learners in Hong Kong in avoiding the error of vocabulary compensation; those translations are so misleading that they may even aggravate such a lexical error committed by the learners.

\subsection{Synforms}

Synforms are defined as words possessing similar morphological structures; notwithstanding not being interrelated to each other, and being essentially distinct in meaning, these words are often confused by learners by virtue of similarities in their shape (Chan 2010). Consider the following pair of sentences:

(20a) I work nearly.

(20b) I work nearby.

Even though both sentences (20a) and (20b) are grammatical, only the latter correctly expresses the proposition intended by the writer, which is "I work in a place that is not far away" in lieu of "I almost work". Consider the componential analyses of the two adverbs:

(21a) Nearly $=$ [not] [completely].

(21b) Nearby $=$ [not] [far]. 
It can be seen that nearly is an intensifier, which indicates the degree of something, whilst nearby is an adverb that indicates position. These two adverbs thereby possess entirely distinct meanings and cannot be used interchangeably. Consider also the following test for a parameter of descriptive meaning:

(22a) I have not nearly done, but I am doing it nearby.

(22b) I am not doing it nearby, but I have nearly done.

Sentences (22a) and (22b) clearly manifest that the two adverbs differ in descriptive meaning, for a substantial disparity exists between the qualities of the two adverbs. In sentence (22a), "I" am doing something in a place that is not far away, but the work is not almost done. In contrast, in sentence (22b), the work that "I" am doing is almost done, but the location where "I" am working is not near.

Learners' confusion of the two adverbs can be accounted for by two plausible explanations: similarity in morphological structure and similarity in grammatical function between the two adverbs. Regarding morphological structure, both adverbs nearly and nearby have the word "near" as the root, albeit barely are the roots of the two words tantamount to each other. On the contrary, the two roots are polysemous in the sense that the root of nearly is an adjective, whilst the root of nearby is an adverb (Oxford English Dictionary 2015). Both words have "near" as the root, and learners may confuse between them easily even though the two words are essentially distinct in meaning. In terms of grammatical function, both adverbs can function as adverbials of sentences.

Between the two aforementioned explanations, the first explanation, which is associated with the morphological similarities between the two adverbs, appear much more conclusive than the second one, in that formal similarities are more obvious and remarkable than functional similarities. Furthermore, seldom is the adverb nearly placed in the sentence final position as in sentence (20a). Nevertheless, for whichever reason learners fail to distinguish between the two adverbs, such a lexical error ought to be avoided assuredly lest the disruption of the transmission of information or messages.

Akin to the analytical method adopted for the first three types of error, the dictionary entries of the two easily confused lexical words in the OALD are presented in Figs. 7 and 8, respectively. The principal distinction between nearly and nearby about which learners ought to be clear is that the former concerns the degree, whilst the latter concerns location. In accordance with Figs. 7 and 8, the dictionary entries provide sufficient lexical information to help learners make a clear distinction between the two: nearly is defined using words like "almost" and "not quite", which are highly correlated with the degree to which something applies, whereas nearby is defined in terms of the word "distance", which provides learners with a clear impression that this adverb is employed to express spatial relationship (Oxford Advanced Learner's Dictionary 2015). The lexical information provided in monolingual dictionaries is thereby said to be able to avoid the error of synforms committed by EFL learners in Hong Kong like that shown in sentence (20a).

It would however even be better if the dictionary was capable of identifying the difference in morphological structure between the two words, revealing to learners 
Fig. 7 The entry of Nearly in OALD. Source "Oxford Advaned Learner's Dictionary". Oxford University Press. Accessed April 20, 2015. http:// www.oxfordlearnersdictionaries. com/

\section{O... nearly adverb}

BrE /'nıəli/ /(p)); NAmE /'nIrli/ /(p))

Add to my wordlist

almost; not quite; not completely

- The bottle's nearly empty.

- I've worked here for nearly two years.

- It's nearly time to leave.

- The audience was nearly all men.

- He's nearly as tall as you are.

- They're nearly always late.

- She very nearly died.

\section{Om nearby adjective}

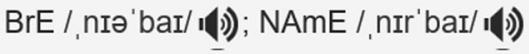

\section{Add to my wordlist}

[usually before noun] near in position; not far away

- Her mother lived in a nearby town.

- There were complaints from nearby residents.

Check pronunciation: nearby

Fig. 8 The entry of Nearby in OALD. Source "Oxford Advaned Learner's Dictionary". Oxford University Press. Accessed April 20, 2015. http://www.oxfordlearnersdictionaries.com/

that the two "near", which are the roots of the two adverbs, are indeed distinct from each other. In this way, it will be less probable for learners to confuse between the two seemingly related lexical items. Consider the Chinese translations of the nearly and nearby provided in the OALED (Hornby 2004):

(23a) nearly: jī hū, chā bù duō, jiāng jìn (幾乎, 差不多, 將近)

(23b) nearby: zài fù jìn, bù yuăn (在附近, 不遠)

These Chinese translations can be utilized to construct the following Chinese sentences: 


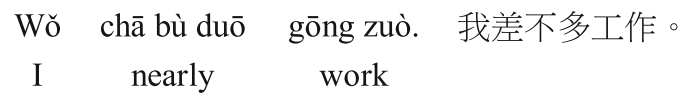

(24a) "I work nearly." or "I nearly work."

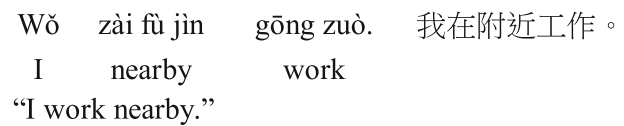

Though possessing entirely distinct meanings, the Chinese translations of the two adverbs are doubtlessly not misleading, but can even assist learners in taking in the meanings of the two English lexical items more easily. Barely can the Chinese translations of nearly, such as 'jī hū', 'chā bù duō', and 'jiāng jìn', be linked to the spatial location, and hardly can the Chinese translations of nearby, such as 'zài fù jìn' and 'bù yuăn', be linked to degree; these Chinese translations are thereby capable of assisting EFL learners in Hong Kong to distinguish between the two adverbs and avoid the error of symforms as in sentence (20a).

\section{Discussion}

The aforementioned analytical results of the four pervasive types of lexical errors committed by EFL learners in Hong Kong will be employed as pieces of evidence to provide answers for the two research questions of the present study.

The first research question concerns whether the lexical information provided by monolingual dictionaries avoids or aggravates the lexical errors committed by EFL learners in Hong Kong. The chief types of lexical information that have to be presented to learners in a bid to assist them in avoiding errors that have been found out to be the sense and syntagmatic constraints of the lexical items. Attributed to the comprehensiveness, accuracy, and adequacy of these two types of lexical information presented in the OALED in response to the four types of lexical errors, the lexical information provided by monolingual dictionaries are argued to be capable of avoiding those lexical errors.

First and foremost, the semantic atoms by which each lexical item is constituted are incorporated into the dictionary entry of that particular lexical item, so that learners can grab the meaning of each lexical item holistically. For instance, the second type of lexical error, synonym confusion, concerns the confusion of near synonyms; the OALD has been found out to be capable of providing sufficient information in the definitions of near synonyms, so that learners can distinguish between them much more easily. The example adopted for illustration is the distinction between fight and hit; the distinction between these two action verbs is chiefly the number of participants involved in physical action, which can be seen in the componential analyses of the two verbs in the previous section. Despite the lack 
of an explicit reference to the number of participants involved in physical action, the definitions provided in the dictionary implicitly remind learners of a distinction between the two verbs, informing learners that fight is used only when a person struggles physically with another person, whilst hit can be used to refer to physical action that is unidirectional. Another concrete instance is the first type of lexical error, inaccurate directionality, which pertains to the paradigmatic sense relation of converses. Converses denote the same event, but are made up of entirely distinct semantic atoms; such a distinction can be clearly observed in the dictionary entries. The example adopted for illustration shows the distinction between lend and borrow. Argument structure is a useful tool for representing the semantic difference between the two lexical items, yet such a concept is hardly accessible to learners who have not studied semantics. The OALD has then made an attempt to incorporate the concept of argument structure into the dictionary entries of the two words using ordinary language. Referring to the entries of the two verbs, learners can easily realize that lend denotes an action performed by the source, whilst borrow denotes an action performed by the goal. These two instances have demonstrated that the lexical information provided in monolingual dictionaries has provided sufficient and accurate information in the sense of lexical items.

Besides the sense of lexical items, monolingual dictionaries have also provided clear information on the syntagmatic constraints of lexical items, so that learners can understand how two lexical items differ in terms of the restrictions on their cooccurrence with other words. For instance, the first type of lexical error, inaccurate directionality, concerns the use of prepositions to indicate directionality. The example adopted for illustration is the distinction between lend and borrow; the syntagmatic constraints of the two verbs play a vital role in indicating their directionality. The two verbs act as selectors, whilst the prepositions following those items are treated as selectees; the preposition to following lend indicates that the prepositional complement following the preposition should be the goal of the action, whereas the preposition from following borrow indicates that the prepositional complement following the preposition should be the source of the action. Overtly stating the syntagmatic constraints of these two words in the respective entries, the dictionary enables learners to understand the directionality of each verb more clearly and avoid the confusion between those two verbs. Another concrete instance is the third type of lexical error, vocabulary compensation, which deals with lexical items that are unrelated in English, but are similar in meaning in the L1. The example adopted for illustration is the distinction between open and turn on; the knowledge on the syntagmatic constraints of the noun phrases that can co-occur with each of these verbs can substantially help learners apply the two lexical items more accurately. As the syntagmatic constraints of these two verbs are rather abstract and complicated, the dictionary barely clearly states the constraints in the entries, but manages to provide prototypical examples of noun phrase that can cooccur with each of the lexical items: open usually co-occurs with doors and windows, whilst turn on usually co-occurs with entities concerning the flow of electricity, water, or gas. It may be argued that the provision of solely the typical examples is inadequate, yet this is reckoned to be good enough an avenue of helping 
learners figure out the distinction between the syntagmatic constraints of the two verbs.

One criticism of the lexical information provided by monolingual dictionaries proposed by Thomson (1987) is the circularity in definitions, which is largely pertinent to the definition of words using difficult words or highly related concepts; barely does such a problem exist in the eight dictionary entries investigated in the present study inasmuch as the definitions are all well written using words that are simpler than the words to be defined. Even for the verb hit, which appears to be a simple word, the definition manages to avoid circulation by vividly describing the motion or body movement of the person performing such an action. The problem of circularity is thereby not detected in the monolingual dictionary under investigation; the entries are reckoned to be fairly easily accessible to EFL learners. Also, providing sufficient information on the sense and the syntagmatic constraints of the vocabulary items, the lexical information provided in monolingual dictionaries is claimed to manage to assist EFL learners in Hong Kong in avoiding the four prevalent lexical errors. Such a result complies with those of Meara and English (1987), which suggest that monolingual dictionaries are largely capable of helping learners identify their own lexical errors.

The second research question concerns whether the Chinese translations provided by bilingual dictionaries avoid or aggravate the lexical errors committed by EFL learners in Hong Kong. It has been found out that the Chinese translations are more useful and profitable to learners given that they can assist learners in distinguishing between the two easily confused words in question; this can only be achieved when the Chinese translations selected share some similar sense properties or syntagmatic constraints with the English lexical items in question. The efficacy of the Chinese translations provided in the OALED is highly dependent on the type of errors which they target.

The Chinese translations provided are argued to be capable of avoiding those lexical errors that are not under the influence of the L1, such as the second and the fourth types of error, which are synonym confusion and synforms, respectively. The roots of these types of errors are probably not interference from the L1, since synonym confusion concerns the failure to differentiate synonyms in English, whilst synforms are lexical items that are morphologically similar in English. Chinese translations may then be profitable for learners to understand the distinction in meaning between the lexical items more clearly. For instance, as for the example adopted for the illustration of synonym confusion, the Chinese translations of fight and hit are 'dǎ jià' and 'dă', respectively. 'dǎ jià' always denotes physical struggles between two or more people, whilst 'dă' always indicates an action in which one person exerts force on another person; since the distinction between the Chinese translations of the two lexical items is the same as that between the two lexical items themselves, those Chinese translations are capable of assisting learners in understanding the difference between the two near synonyms in English. Another type of lexical error is synforms; the example adopted for illustration is the distinction between nearly and nearby, which possess entirely distinct Chinese translations. As it is implausible for native Chinese speakers to confuse 'chā bù duō', the Chinese 
translation of nearly, with 'zài fù jìn', the Chinese translations of nearby, those translations are absolutely capable of assisting learners in distinguishing between the two synforms. The aforementioned results concur with the findings of Cook (2001) that learners' linguistic knowledge of the L1 can facilitate the uptake of the linguistic knowledge of the target language.

The Chinese translations provided are however not always profitable, in particular when it comes to certain types of error that are highly under the influence of the L1; the problems with the Chinese translations are especially serious for the third type of error, vocabulary compensation. As suggested above, the chief purpose or function of the Chinese translations is to help learners distinguish between some easily confused English words to avoid making lexical errors that substitute a wrong word for a correct word. Given that the same Chinese translation is provided for two distinct English lexical items, the Chinese translation will not be capable of achieving the aforementioned purpose. For instance, the Chinese linguistic expression 'dă kāi' is adopted as the Chinese translation of both open and turn on, two lexical items that are easily confused by EFL learners in Hong Kong. In this way, having looked up the dictionary for the Chinese translations of the two English verbs, learners may likely have a perception that the two verbs mean the same on account of the same Chinese translation shared by them. Another case is that the Chinese linguistic expression ' $k a \bar{i}$ qrè is adopted as the Chinese translation of open, yet it can also mean turn on in some syntactic environments and contexts. Native Chinese speakers may then get confused and misinterpret open and turn on as equivalents. The Chinese translations provided in bilingual dictionaries may thereby sometimes be misleading when the Chinese linguistic expressions scarcely differ as the English lexical items do; Chinese translations that are misleading may induce EFL learners to wrongly treat different English lexical items as equivalents and commit lexical errors; this is compatible with the results of the study conducted by Thomson (1987) that direct translations in bilingual dictionaries may sometimes be disastrous to learners and effectuate the production of lexical errors.

One final point to be noted is that only the second research question deals with the efficacy of the Chinese translations provided in bilingual dictionaries in avoiding the lexical errors committed by EFL learners in Hong Kong in lieu of the efficacy of bilingual dictionaries as a whole. The reason why a clear distinction has to be made between the Chinese translations provided in bilingual dictionaries and the entirety of bilingual dictionaries is that the lexical information in bilingual dictionaries comprises both the lexical information presented in monolingual dictionaries and the Chinese translations of English lexical items. As all the lexical information presented in monolingual dictionaries is present in bilingual dictionaries, there is no point in commenting on the lexical information, which has already been evaluated in the first research question and in the second research question; but the second research question pinpoints and specifies the Chinese translations in bilingual dictionaries instead. 


\section{Limitations}

Despite the provision of some meaningful observations and discussion on the impacts of the lexical information provided by monolingual and bilingual dictionaries on the lexical errors committed by EFL learners in Hong Kong, the present study possesses two overarching limitations: insufficient samples and inadequate evidence.

To begin with, the present research possesses too small a sample size in two aspects, the first of which concerns the coverage of errors. Four types of lexical errors prevalently committed by EFL learners in Hong Kong have been identified in this study; only one example of each error is analysed for each type of error, which is irrefutably insufficient for generalization. More samples of each type of error should have been analysed in a bid to find out whether the lexical information provided in monolingual dictionaries and the Chinese translations provided in bilingual dictionaries are truly sufficient, accurate and comprehensive for learners to avoid those lexical errors. The analysis of merely one example for each type of error may provide readers with an impression that the entire study has overgeneralized some observations in lieu of providing a genuinely conclusive evaluation and discussion. For instance, three to four examples can be analysed for each type of error, one of which can be analysed in length whilst the other examples can be discussed briefly. The in-depth analysis of one of the examples serves as an exemple, revealing how the analytical process is carried out whereas the incorporation and mention of two to three more examples are meant to enhance the convincing power of the entire study.

Another limitation as regards the sample size associated with the use of dictionaries, because onlythe OALD and the OALED are taken into account in the present study. These two dictionaries have been chosen for some reasons, which have been stated in Sect. 3 of this paper, albeit this study aims at investigating the impacts of monolingual dictionaries and bilingual dictionaries at large in lieu of dictionaries published by the Oxford University Press. The entries of more monolingual and bilingual dictionaries should thereby be taken into account in the analysis, so that the entire study can be more meaningful and insightful. Given that the entries of more dictionaries are analysed and the results comply with those of the present study, the conclusion drawn can be much more definite and convincing. In contrast, even if the efficacy of distinct dictionaries or the comprehensiveness of the lexical information presented in different dictionaries differ, insightful discussions can still be put forward by recommending certain monolingual or bilingual dictionaries over others for the purpose of avoiding lexical errors. However, given that more dictionaries are analysed, the entire study will involve more processes and so be much more complicated; a systematic analytical methodology then has to be proposed in a bid to inform readers of how an enormous quantity of information can be organized and analysed in a systematic and well-organized fashion.

Apart from insufficient samples, inadequate evidence is also a limitation of the present study. The entire study lays basis upon a crucial assumption that only does the lexical information provided in dictionaries assist EFL learners in Hong Kong 
in avoiding their lexical errors by targeting on the gaps or misconceptions in learners' lexical knowledge. Given that such an assumption is incorrect, the entire study will be invalid. As a matter of fact, whether the dictionaries are helpful does not only hinge on the lexical information provided, but also depends on the learners themselves. Even though the dictionaries are capable of providing comprehensive lexical information that is presumed to be capable of filling the gaps of their lexical knowledge or clarifying their misconceptions, given that the English proficiencies of the learners are so low that the learners fail to interpret the lexical information presented, all the lexical information presented will be useless to them. For instance, Chan (2011) has discovered that some dictionary information may be ignored by learners, which may be accounted for by their preoccupation with typical word collocations and typical usages of words. The learner factor thereby plays a crucial role in the present study, yet never is such a factor taken into consideration throughout the entire study, which solely investigates the errors using semantic theories and concepts as well as dictionary entries without testing or looking into the real response of learners after reading the dictionary entries. The design of the study can be improved by comparing the lexical knowledge of a certain group of subjects before and after reading the dictionary entries. Given that they commit those lexical errors before reading the dictionary entries and no longer commit such errors after reading the entries, it will be more convincing to conclude that the lexical information presented in dictionaries is capable of avoiding the lexical errors committed by EFL learners in Hong Kong.

\section{Conclusion}

By and large, it is in evident that the lexical information provided in monolingual dictionaries avoids the lexical errors committed by EFL learners in Hong Kong, whilst the Chinese translations provided in bilingual dictionaries may sometimes be misleading and so aggravate the lexical errors committed by learners. Addressing and targeting on the gaps and misconceptions in learners' lexical knowledge, the lexical information provided in monolingual dictionaries are capable of informing learners of the sense and syntagmatic constraints of lexical items, assisting them in differentiating between easily confused words and avoiding lexical errors. While the Chinese translations of some lexical items manage to help learners understand the meaning of English lexical items more clearly and easily, some of them have a propensity to lead learners to treat separate English lexical items as equivalents and misuse some of the words.

The results of the present study can contribute to the field of second or foreign language instruction in the sense that EFL learners ought to be encouraged to cultivate a habit of looking up monolingual dictionaries for the usage of words. It is not uncommon to see learners looking up bilingual dictionaries in lieu of monolingual dictionaries, and they tend to look up the dictionaries chiefly for checking the meaning of difficult words while reading in lieu of looking for the correct usage of words while writing; such a phenomenon has to be altered 
(Thomson 1987). As proven in the present study that the Chinese translations provided in bilingual dictionaries may be misleading at times, it is advised that elementary EFL learners, who do not possess much English lexical knowledge, resort to monolingual dictionaries in lieu of bilingual dictionaries to avoid misconceptions generated about the meanings of certain lexical items. Learners are also suggested to utilize monolingual dictionaries while writing English pieces, as one probable reason why EFL learners commit so many lexical errors is that they are unaware of the gaps and misconceptions in their lexical knowledge. Given that EFL learners are aware of their gaps and misconceptions, and are willing to look up the dictionaries for the genuine meaning and syntagmatic constraints of words about which they are uncertain, it will obviously be less likely for them to commit lexical errors. The Chinese translations in bilingual dictionaries being useful at times, bilingual dictionaries ought not to be prohibited; yet, it is better for EFL learners to use such dictionaries under the guidance of teachers, who can preclude learners from being misled by those translations.

The final remarks of this paper include some suggestions for future research. Due to the limitations of the present study, discussed in the previous section, the present study can only be construed as a preliminary investigation into the impacts of the lexical information provided in monolingual and bilingual dictionaries on the lexical errors committed by EFL learners in Hong Kong; some research projects that are better designed ought to be conducted in the future in a bid to validate the conclusions drawn in this study. A suggested research project comprises four steps, the first of which is the collection of a considerable amount of written works produced by EFL learners in Hong Kong, followed by the categorization of the lexical errors detected in the scripts. The second step is the analysis of the various types of errors, which can be done through semantic analysis, as conducted in the present analysis, as well as interviews with target groups about the reasons why such errors are committed. More samples have to be taken into account in the semantic analysis, and the sample size of the target group should be large enough so that the results can be more reliable. The third step is the analysis of dictionary entries, which is similar to the analysis conducted in the present study except that more dictionaries have to be analysed so that the entire study can be more representative of monolingual and bilingual dictionaries. The final step is an experiment that compares learners' lexical knowledge before and after reading the dictionary entries of relevant lexical items; this step serves to provide empirical support for the results of the analysis of dictionary entries in the third step. It is hoped that this proposed research project can be conducted in the future, so that the results of the present study can be verified, and more useful pedagogical suggestions can be provided for EFL teachers to devise pedagogies correlated with vocabulary learning that cater to EFL learners in Hong Kong.

\section{References}

Carter, Ronald. 1987. Vocabulary: applied linguistics perspectives. Boston: Unwin Hyman.

Chan, A.Y.W. 2010. Toward a taxonomy of written errors: investigation into the written errors of Hong Kong cantonese ESL learners. TESOL Quarterly 44: 295-319. 
Chan, A.Y.W. 2011. The use of a monolingual dictionary for meaning determination by advanced cantonese ESL learners in Hong Kong. Applied Linguistics 33: 115-140.

Chu, Karson. 2005. Written english errors: a case study of one secondary school in Hong Kong. Master dissertation, The University of Hong Kong, Hong Kong.

Cook, Vivian. 2001. Using the first language in the classroom. Canadian Modern Language Review 57: 402-423.

Cruse, Alan. 2011. Meaning in language: An introduction to semantics and pragmatics, 3rd ed. Oxford: Oxford University Press.

Ellis, Rod. 1997. Second language acquisition. Oxford: Oxford University Press.

Ellis, Rod. 2002. The place of grammar instruction in the second/foreign language curriculum. In New perspectives on grammar teaching in second language classrooms, ed. Eli Hinkel, and Sandra Fotos, 17-34. Mawah: Lawrence Erlbaum Associates.

Ellis, Rod. 2006. Current issues in the teaching of grammar: an SLA perspective. TESOL Quarterly 40: $83-107$.

Fillmore, Charles J. 1971. Types of lexical information. In Semantics: an interdisciplinary reader in philosophy, linguistics and psychology, ed. Danny D. Steinberg, and Leon A. Jakobovits, 373-392. London: Cambridge University Press.

Greenbaum, Sidney, and Randolph Quirk. 1990. A student's grammar of the english language. London: Longman.

Hornby, A.S. 2004. Oxford advanced learner's English-Chinese dictionary, 6th ed. Hong Kong: Oxford University Press.

Jim, Mei-hang. 2005. A study of lexical errors in Cantonese ESL students' writing. Master dissertation, The University of Hong Kong, Hong Kong.

Littlewood, William, and Yu. Baohua. 2011. First language and target language in the foreign language classroom. Language Teaching 44: 64-77.

Meara, Paul, and Fiona English. 1987. Lexical errors and learners' dictionaries. Malet St: Birkbeck College, London University.

Nation, I.S.P. 2001. Learning vocabulary in another language. Cambridge: Cambridge University Press.

Nelson, Gerald. 1998. The internet grammar of english. University College London. http://www.ucl.ac. uk/internet-grammar/.

Ortega, Lourdes. 2009. Understanding second language acquisition. London: Hodder Education.

Oxford Advaned Learner's Dictionary. Oxford University Press. Accessed April 20, 2015. http://www. oxfordlearnersdictionaries.com/.

Oxford English Dictionary. Oxford University Press. Accessed April 20, 2015. http://www.oed.com/.

Richard, Jack C. 1976. The role of vocabulary teaching. TESOL Quarterly 10: 77-89.

Thomson, Geoff. 1987. Using bilingual dictionaries. ELT Journal 41: 282-286.

Turnbull, Miles. 2001. There is a role for the L1 in second and foreign language teaching, but.... Canadian Modern Language Review 57: 531-540.

Yule, George. 2014. The study of language, 5th ed. Cambridge: Cambridge University Press. 